\title{
Qatari Tight Gas Reservoirs: Molecular Simulation Insights Toward the Estimation of Ultimate Recovery (EUR) from Carbonated Reservoirs
}

\section{ABSTRACT}

The geometrical properties of the reservoir rocks are usually affected by natural thermodynamics or environmental changes that may affect the amount of gas in place in the reservoir. To address these properties, we conduct DFT calculations to study the effect of gas composition on the gas adsorption, including, surface strain and curvature effects. Additional analysis like geometrical analysis, and surface energy were conducted and calculated to explain the results. These findings can be useful for determining the estimated ultimate recovery in carbonaceous tight gas reservoirs.

\section{Methodology}

a. Creating the model of the porous media by Material Studio

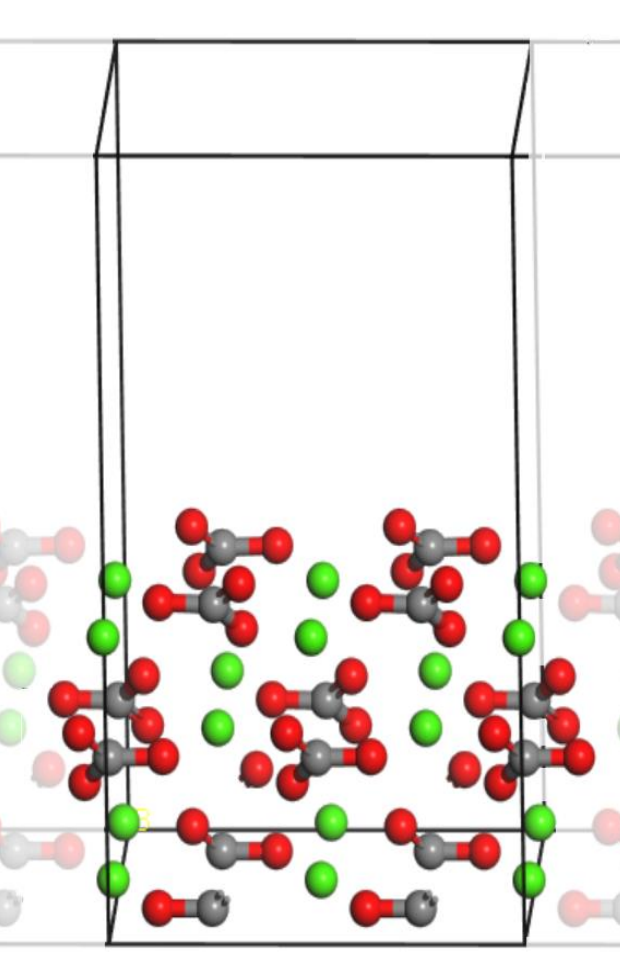

1. Flat surface

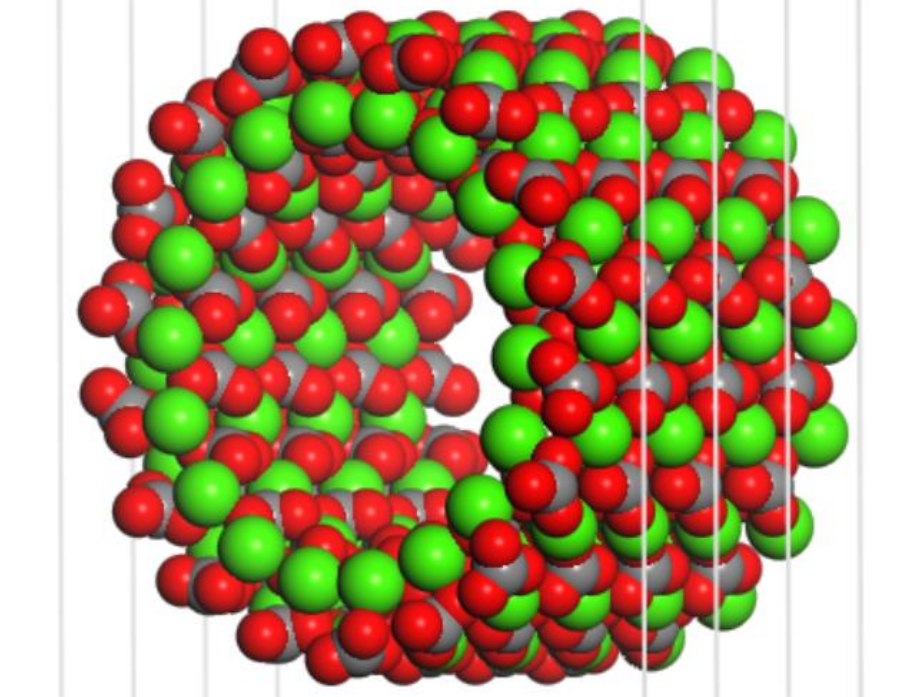

2. Cylindrical surface
Introduction \& Objectives
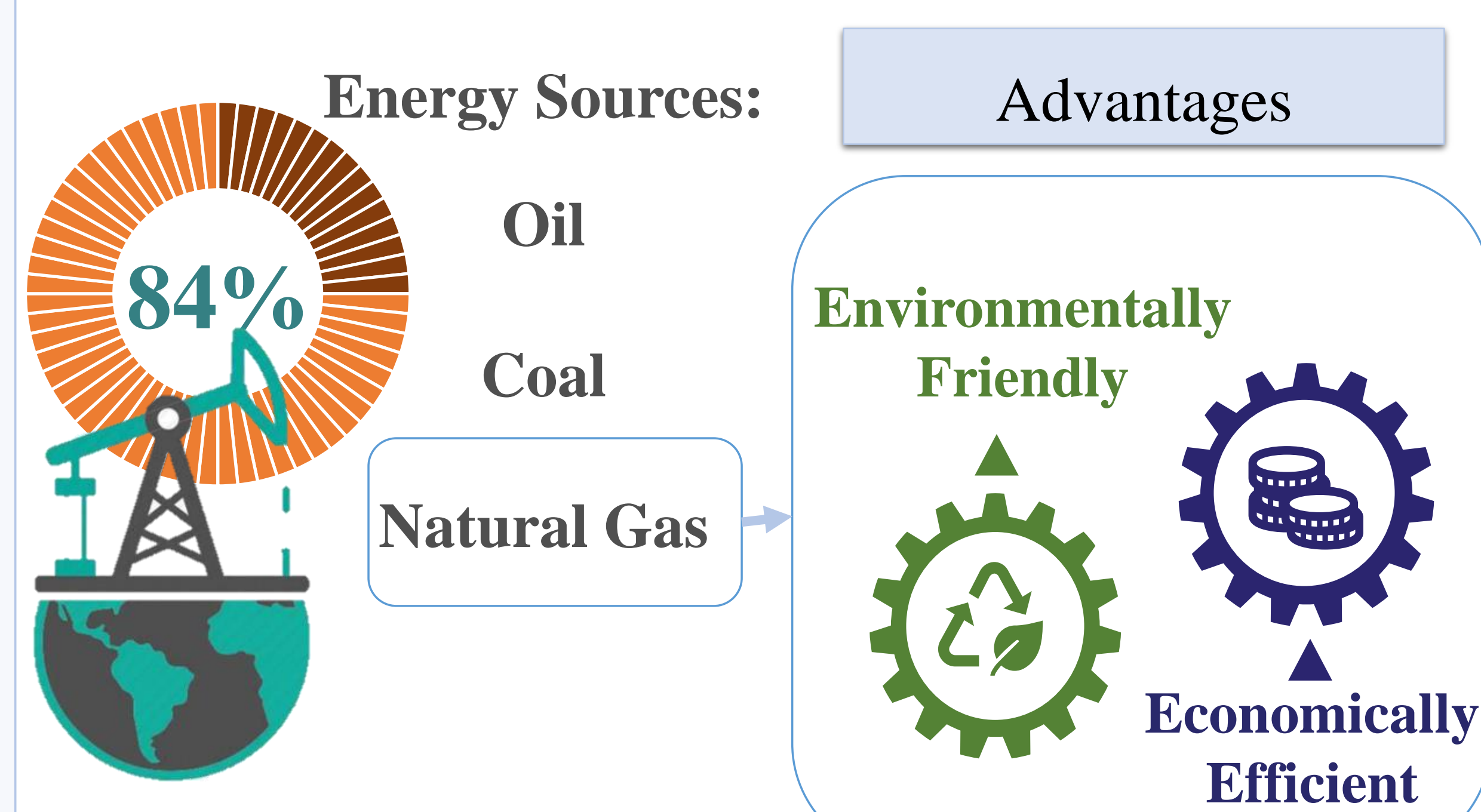

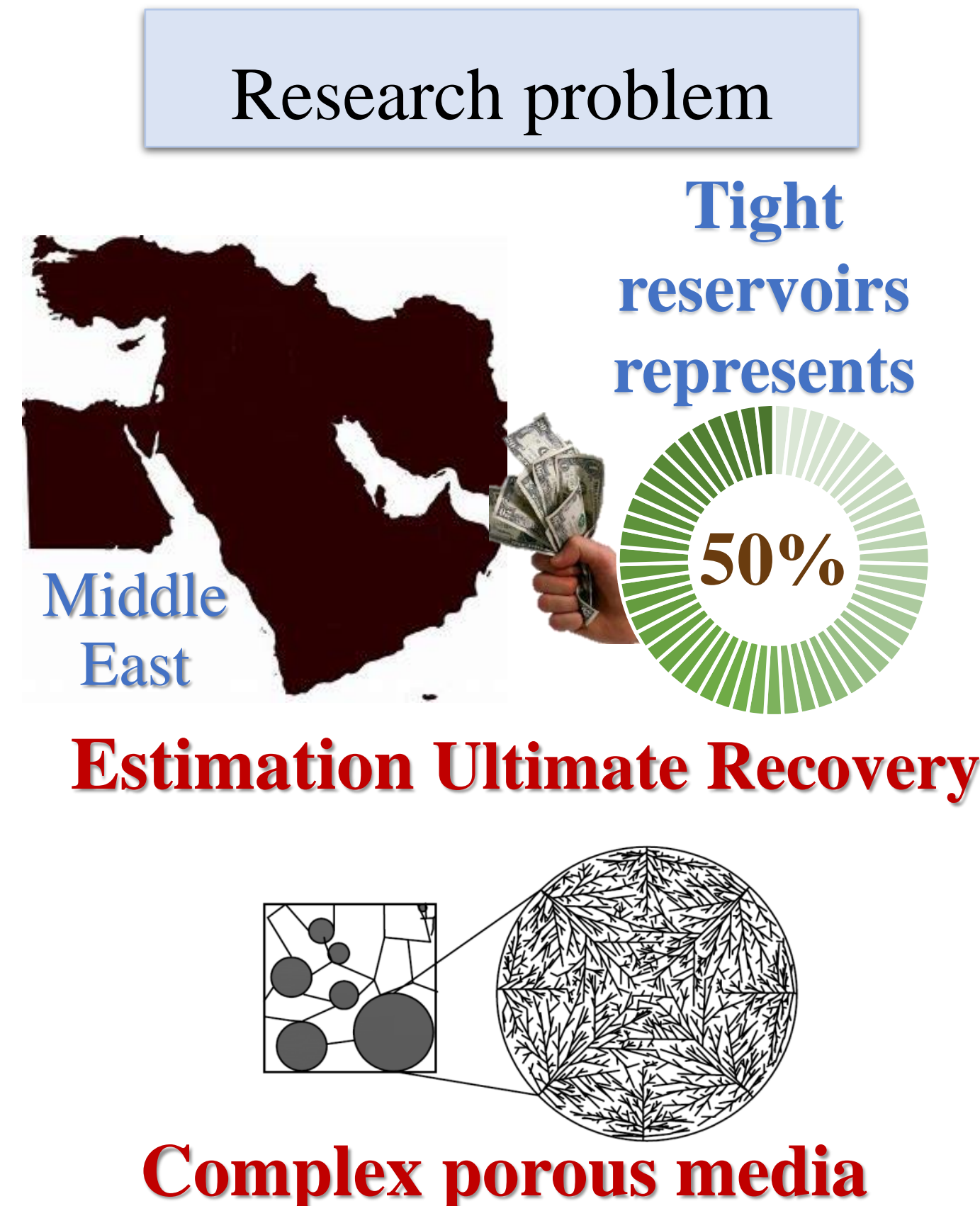

Complex porous media
Objective

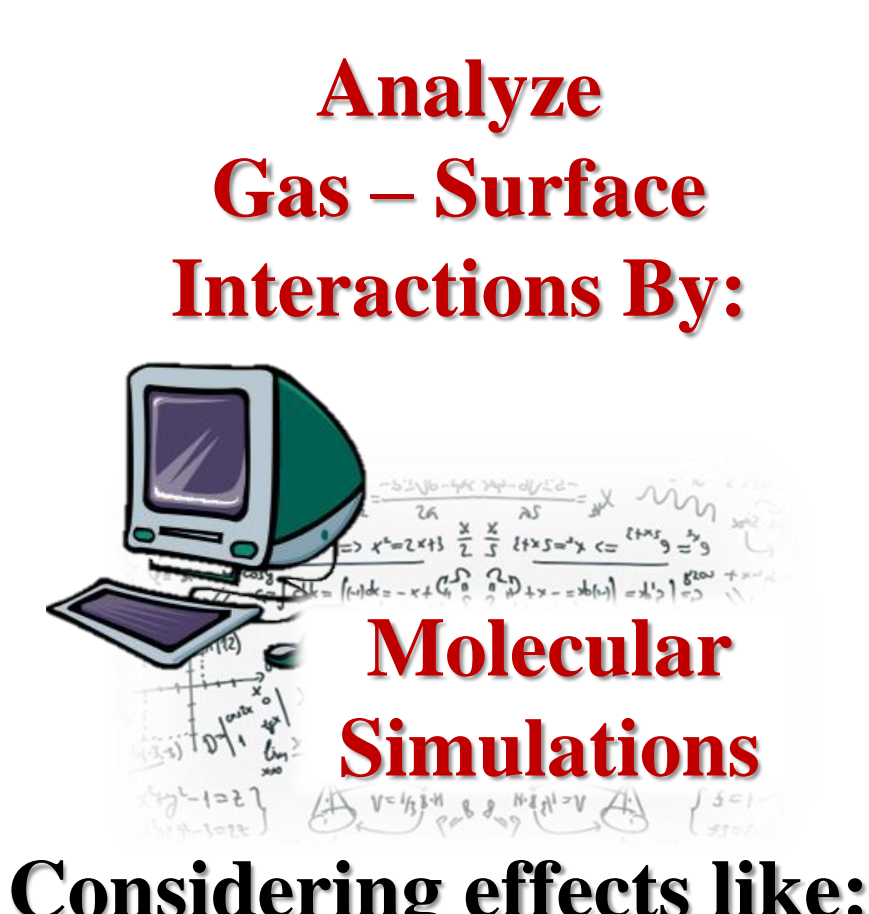

a. Surface strain

b. Curvature \&

Nanopore diameter

Results \& Discussions

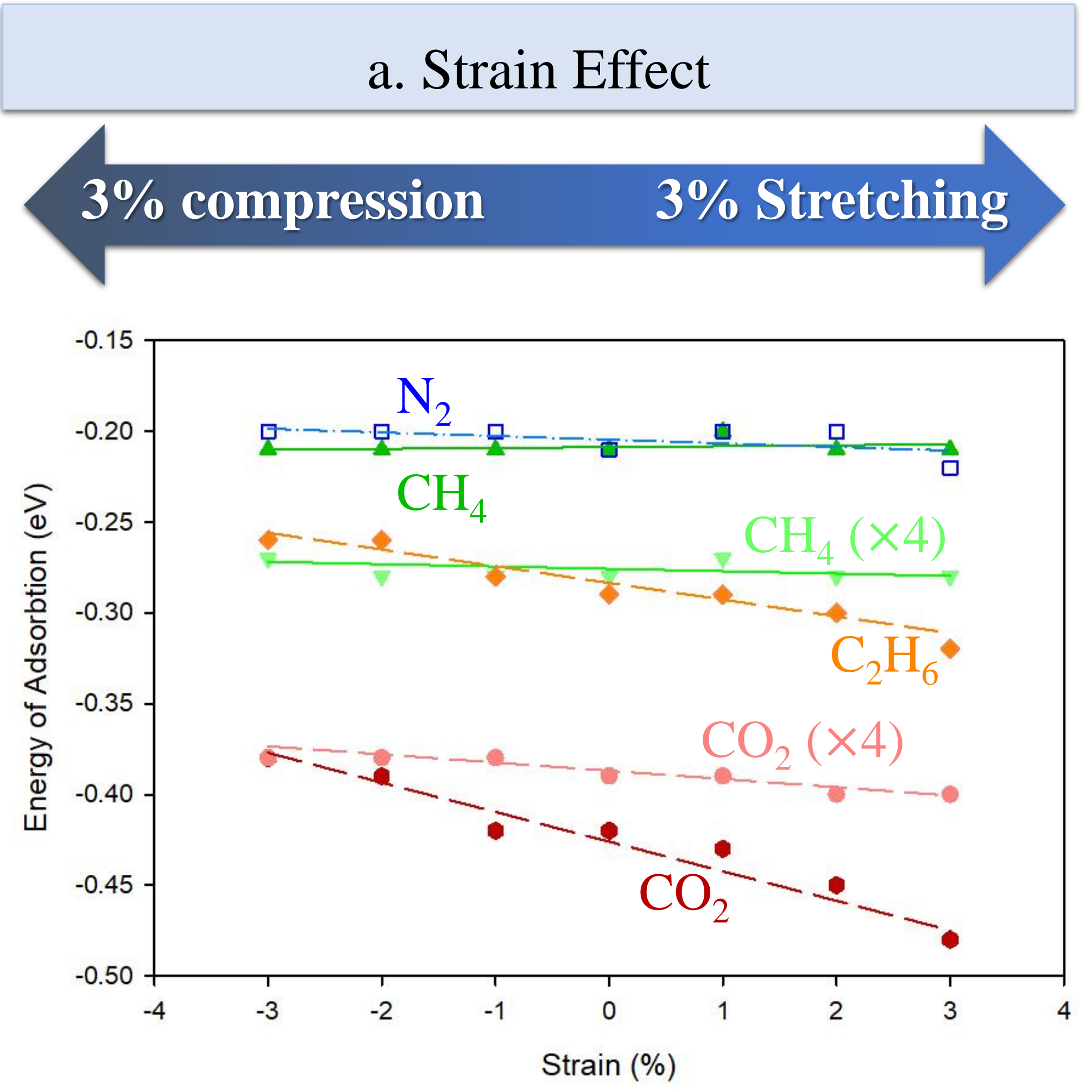

Figure 1: $\mathrm{E}_{\text {ads }}$ of different gases on strained surfaces.

d. Capacity Test

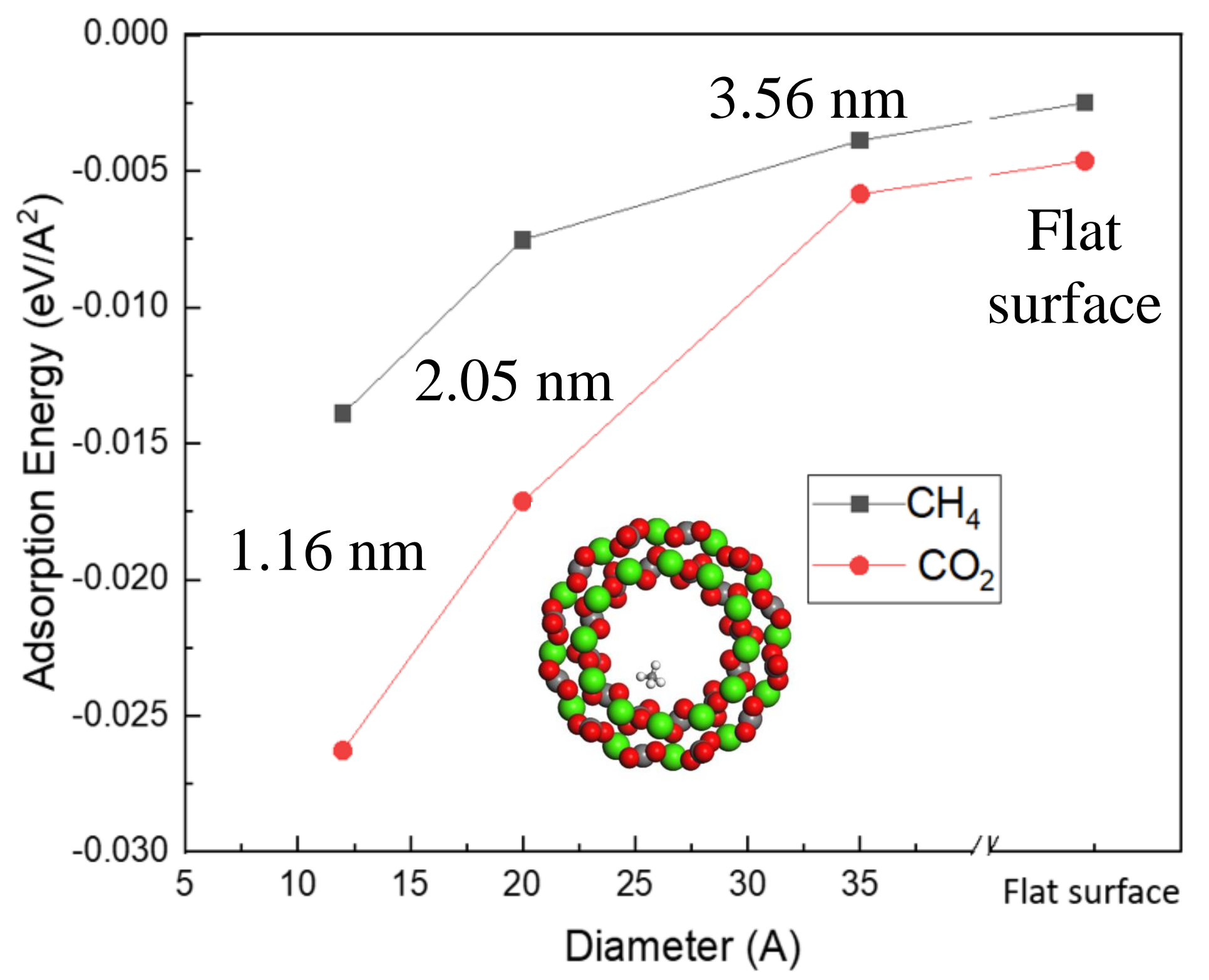

Figure 3: $E_{a d s}$ of the three nanopores and the flat surface.

Developed mathematical model:

$C_{4}: \operatorname{Ln}\left[-E_{\text {ads }}\right]=-5.106-0.066 \times D \quad R^{2}=0.995$ (3)

$\mathrm{CO}_{2}: \operatorname{Ln}\left[-E_{\text {ads }}\right]=-6.002-0.054 \times D \quad R^{2}=0.977(4)$

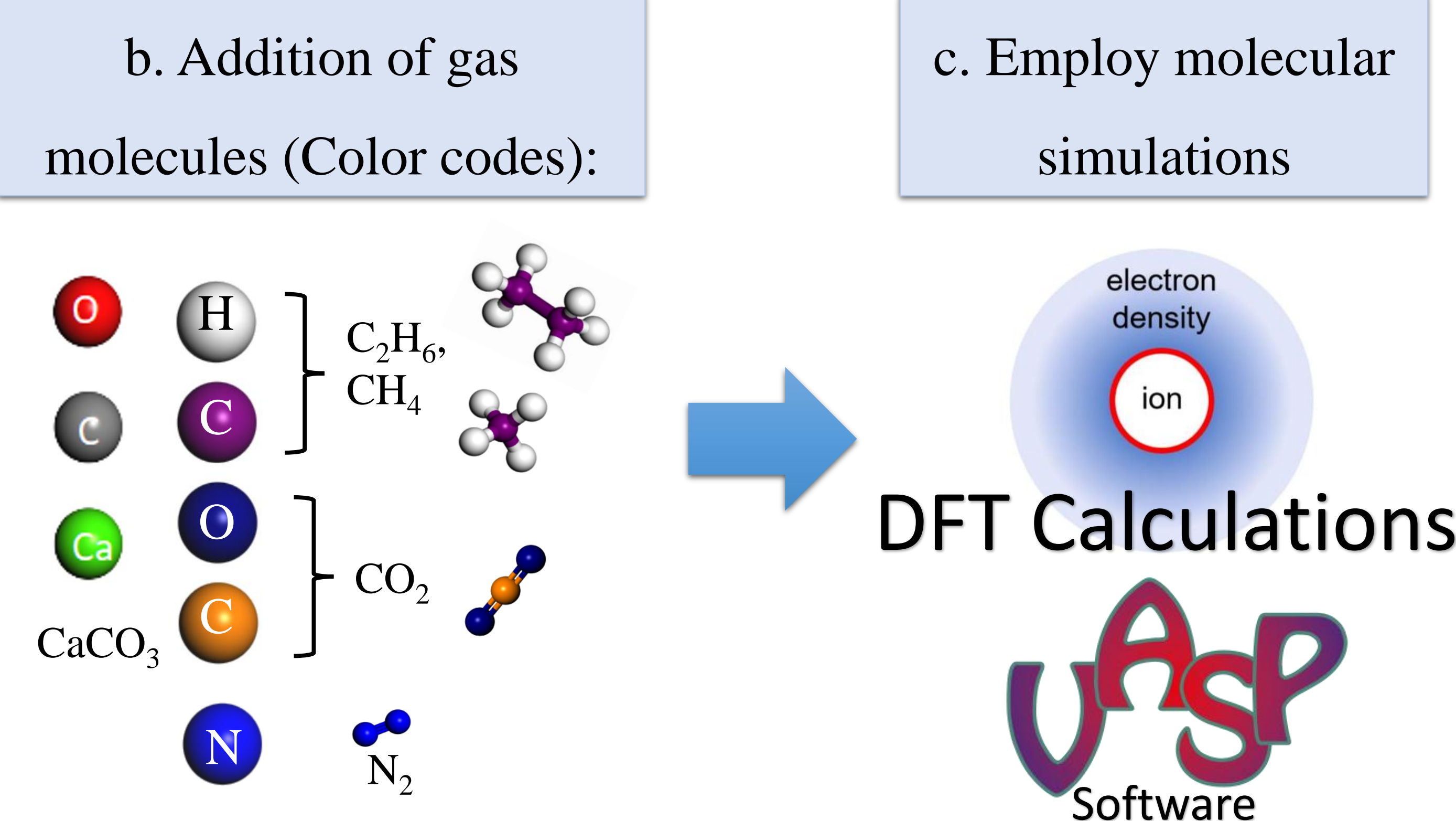

c. Analysis \&

Equations

Geometrical Analysis \& Surface Energy $(\gamma)$ $\gamma=\frac{\left(E_{\text {SURF }}-n E_{\text {bulk }}\right)}{\left(A_{\text {inner }}+A_{\text {outer }}\right)}$

Adsorption Energy $\left(E_{a d s}\right) \&$ Capacity Test

$$
E_{a d s}=\frac{E_{S U R F+N X}-E_{S U R F}-\left(N \times E_{X}\right)}{N}(2)
$$

c. Geometrical Analysis

Table 1: The geometric properties of the nanopores and the flat surface.

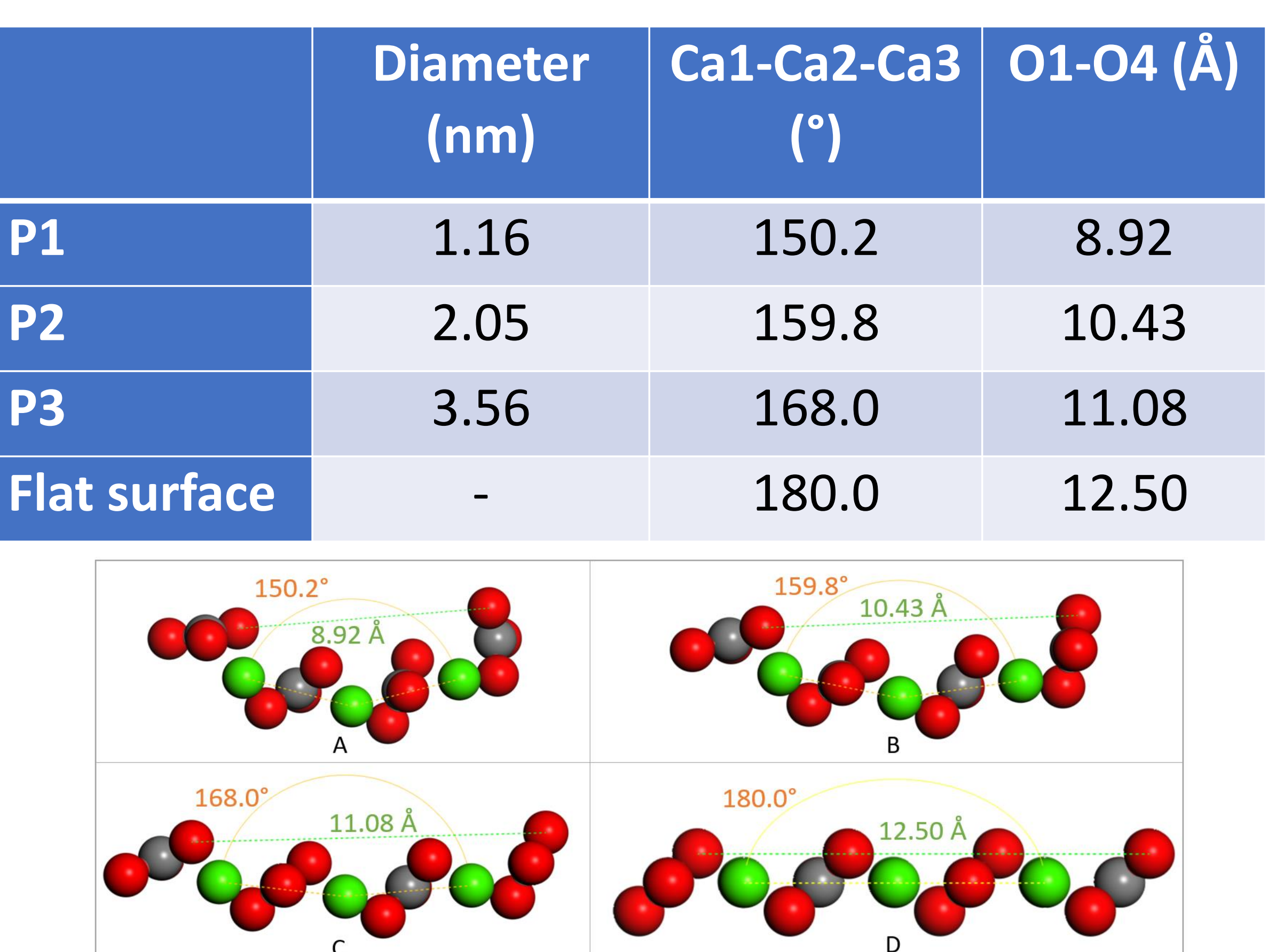

Figure 2: surface energy showing an increase with decreasing the curvature effect.

e. Capacity Test
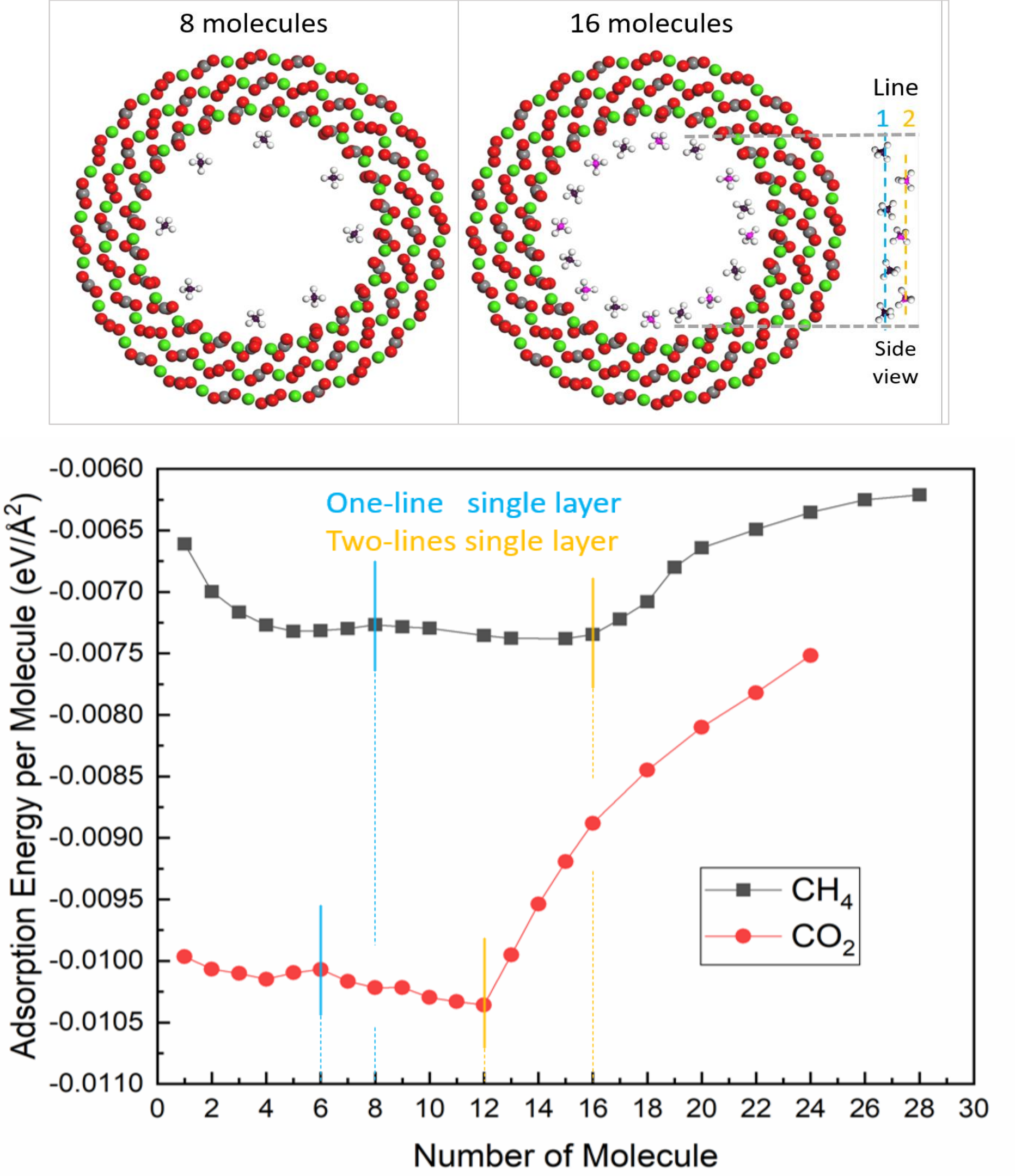

Figure 4: Capacity test for adsorption energy of $\mathrm{CH}_{4}$ and $\mathrm{CO}_{2}$ per molecule.
Conclusions

$>$ All the studied gases were physiosorbed to the surface, with $\mathrm{CO}_{2}$ having higher adsorption energy in all cases.

$>$ The affinity of specific gases to the surface increases with stretching, and the result differ with gases conc.

$>$ Curved nanopore surfaces have more surface energy and different geometrical properties resulting in higher gas adsorption affinity compared to the flat surface.

$>$ The cylindrical nanopore absorbed more than 24 molecules of both $\mathrm{CH}_{4}$ and $\mathrm{CO}_{2}$ with alteration of $\mathrm{E}_{\mathrm{ads}}$ with formation of new layers.

$>$ Three papers are published as outcomes of this work.

References

1. E. Elbashier, I. Hussein, G. Carchini, A. Sakhaee Pour, G.R. Berdiyorov, Effect of strain on gas adsorption in tight gas carbonates: A DFT study, Comput. Mater. Sci. (2020) 110186. E. Elbashier, I. Hussein, G. Carchini, A. Kasha, G. Berdiyorov. Influence of natural gas composition on adsorption in
Volume 568 (2021) 150940.

G.R. Berdiyorov, E. Elbashier, G. Carchini, I.A. Hussein, A. Sakhaee-Pour. The effect of vacancy defects on the adsorption of methane on calcite 104 surface, Journal of Materials 